\begin{tabular}{llll}
\hline $\begin{array}{l}\text { Age } \\
\text { Mean (CI) (n) }\end{array}$ & $\begin{array}{l}\text { Total } \\
\text { Boys } \\
\text { Mean (CI) (n) }\end{array}$ & \multicolumn{1}{c}{$\begin{array}{l}\text { Girls } \\
\text { Mean (CI) (n) }\end{array}$} \\
$10-13$ yrs & $85.4(84.7-86.2)(1146)$ & $85.6(84.6-86.7)(523)$ & $85.3(84.2-86.3)(623)$ \\
10 yrs & $87.6(85.0-90.1)(73)$ & $88.2(83.7-92.8)(24)$ & $87.2(84.1-90.4)(49)$ \\
11 yrs & $85.9(84.7-87.1)(488)$ & $86.6(85.1-88.1)(217)$ & $85.3(83.6-87.0)(271)$ \\
12 yrs & $84.7(83.5-85.8)(499)$ & $84.3(82.6-86.0)(229)$ & $85.0(83.4-86.6)(270)$ \\
13 yrs & $85.1(82.8-87.5)(84)$ & $85.7(82.7-88.7)(51)$ & $84.3(80.4-88.1)(33)$
\end{tabular}

self-report scales: comparison of mothers' and children's reports. J Nerv Ment Dis 1980; $168: 736-40$

5. Fendrich $M$, Weissman MM, Warner V. Screening for depressive disorder in children and adolescents: validating the Center for Epidemiologic Studies Depression Scale for Children. Am J Epidemiol 1990; 131: 538- 551.

Frank Houghton

Dept. of Humanities, Limerick Institute of Technology Limerick

Hilary Cowley

Dept. of Public Health, HSE Mid-Western Area Limerick

Fiona Meehan

Mary Immaculate College

Limerick

Kevin Kelleher

Dept. of Public Health, HSE Mid-Western Area

Limerick

Ireland.

\section{Psychiatric morbidity in prisoners}

Dear Editor - I read with interest the large scale study by Linehan et al on Psychiatric Morbidity in Prisoners. This is a very important study because of the large numbers involved and because a structured demographic interview was used. I was looking for information on very important psychiatric diagnosis among prisoners, Pervasive Development Disorders/Asperger's syndrome, and Pervasive Developmental Disorder Not Otherwise Specified as well as Attention Deficit Hyperactivity Disorder. I was surprised not to find any comment on these diagnosis which are so important in modern Forensic Psychiatry.

Scragg and Shah found the rate of Asperger's syndrome in a Secure Hospital between 1.5\% - 2.3\%. This is higher than in the general population. In a pilot study by Curran and Fitzgerald found increased rates of Attention Deficit Hyperactivity Disorder in Mountjoy Prison compared to the general population. As it was a pilot study it needs to be done using larger numbers. It is critical that a study now to be done in an Irish prison population of the Pervasive Developmental Disorders including Asperger's syndrome, Autism, Pervasive Developmental Disorder Not Otherwise Specified, as well as Attention Deficit Hyperactivity Disorder as it is my impression that there are significant numbers of these in prison population who are undiagnosed and of course then by definition not treated.

\section{References}

1.Linehan S., Duffy D., Wright B., Curtin K., Monks S., Kennedy H. Psychiatric morbidity in a cross sectional sample of male remanded prisoners. Irish Journal of Psychological Medicine, 2005, 22(4), 128-132

2.Scragg P., Shah A. Prevalence of Asperger's syndrome in a Secure Hospital. British Journal of Psychiatry, 1994, 165: 679-82.

3.Curran S., Fitzgerald M. Attention Deficit Hyperactivity Disorder in a prison population. American Journal of Psychiatry, 1999, 156, 10, 1664-1665.

Michael Fitzgerald Henry Marsh Professor Child \& Adolescent Psychiatry Trinity College Dublin Ireland.

\section{Pimozide treatment for body dysmorphic disorder}

Dear Editor - McWilliams et a/ are to be commended on their interesting and informative case report on body dysmorphic disorder published in the Irish Journal of Psychological Medicine. ' We have recently treated an outpatient with body dysmorphic disorder and we wish to make some points that may be of interest to your readers, relating to both the phenomenology and pharmacolotherapy of this condition.

In summary, the case is that of a 46 year old married man, newly referred to our outpatient department with no previous contact with the psychiatric services. The initial diagnosis made was that of a major depressive episode with associated obsessional ruminations regarding acne rosacea, subsequently revised to major depression and body dysmorphic disorder. Symptoms of acne rosacea had been present to a varying degree for the previous seventeen years, despite little objective evidence of any skin problems on examination. He had consulted dermatologists and had numerous courses of antibiotic treatment but was never satisfied with the outcome.

The phenomenology was interesting, involving obsessional ruminations regarding the acne rosacea, mirror-checking and social avoidance with associated low self-esteem and depressed mood. Analogous to the phenomenology seen in anorexia nervosa, it was sometimes difficult to establish if the patient's beliefs could be defined as overvalued ideas or delusional in nature.

He was initially treated with sertraline (up to $150 \mathrm{mg}$ per day) and risperidone (up to $6 \mathrm{mg}$ per day) but did not respond. His mood became more depressed and he took an 
overdose of his medication, with a high level of suicidal intent. Sertraline was subsequently changed to venlafaxine, with little effect, despite the dosage being raised gradually to a level $300 \mathrm{mg}$ per day. Finally, pimozide $4 \mathrm{mg}$ once daily was then added in place of risperidone. This change led to a significant and rapid amelioration in symptoms, without any clinical psychological input as yet, an improvement that was sustained up until six weeks of outpatient follow-up, the patient's most recent review.

Therefore, despite the reservations of Philips et al in their study, cited in the case report of McWilliams et al, pimozide may yet have a role in the treatment of this challenging and complex condition.
References

1. McWilliams S, Whitty M, Lydon D, Clarke M. Body dysmorphic disorder treated with venlafaxine, olanzapine and cognitive behavioural therapy. Ir J Psych Med 2005 22(4):143-146.

2. Philips KA. Placebo-controlled study of pimozide augmentation of fluoxetine in body dysmorphic disorder. Am J Psychiatry 2005:162(2):377-9.

Henry O'Connell, MRCPsych.

Senior Registrar in Psychiatry

Limerick Mental Health Services

Patrick G Doyle, MRCPsych.

Consultant Psychiatrist

Limerick Mental Health Services

Tevere Day Hospital, Shelbourne Road

Limerick

Ireland.

\section{Walter Freeman - maverick medical genius?}

The Lobotomist: a maverick medical genius and his tragic quest to rid the world of mental illness. Jack El-Hai. Wiley. 2005. 368 pp. £19.99/€24.30 ISBN 0 471232920.

Jack El-Hai found Walter Freeman (1895-1972) 'a biographer's dream: an engaging writer with a substantial ego who recorded his thoughts in countless books, articles, letters, journals and memoirs', rich in outrageous or controversial speculation though poor in personal revelation.

A maverick but hardly a genius, Freeman despised his father's easy-going approach to his otolaryngology practice in Philadelphia while his father's father-in-law, WW Keen, dominated the surgical scene.

Freeman soon decided that he would have to be as famous as his grandfather Keen - without his earnestness.

From his grand tour of European clinics, Freeman was recalled to the post of senior medical officer in the laboratories of St Elizabeth's Hospital in Washington DC, "a golden apple had nicely fallen into his lap" the tree shaken by old Keen.

In 1932 Freeman transferred to George Washington University as director of neuropathology. A year later at the American Neurological Association a young surgeon James Watts was entranced by the magnetic vigour of Freeman's presentation, and a few months later was invited to come to the University as professor of neurosurgery, for Freeman had branched into clinical neurology.

In 1935 Freeman attended the Second International Neurological Congress in London; there Carlyle Jacobsen reported investigations he had been making in John Fulton's lab at Yale on intellectual and behavioural deficits after frontal lobectomy. They reported profound changes in two young chimpanzees in which 'experimental neurosis' was dramatically relieved by bilateral frontal lobectomy.

Antonio Caetano Abreu Freire Egas Moniz returned from the London Congress to Lisbon and by November had persuaded
Almeida Lima to perform prefrontal leucotomy by injecting alcohol into the brain substance. Dissatisfied with the initial results, Lima changed to using a knife - a leucotome.

Moniz was aware that his procedure did not eliminate their patients' delusions and hallucinations; it diminished their emotional response to these symptoms without, he assumed, impairing intellect. A paper describing nine cases appeared within weeks followed by an equally hasty monograph.

As soon as he read about it Freeman shot off a sycophantic letter to Lisbon. He had discovered the road to fame. Surgeon Watts wielding the leucotome was a stumbling block, so the physician decided to work without him and devised a six-minute transorbital lobotomy using an ice-pick while the patient was stunned after an electric shock. When his procedure was prohibited by George Washington University, Freeman literally took to the road and operated on hundreds of patients in state institutions which by the late 1940s were filled to overflowing with mind-mangled veterans from WWII.

When Moniz shared the Nobel Prize in 1949 for 'pioneering this therapeutic triumph' (not for cerebral angiography which he introduced in 1934) Freeman and Fulton felt cheated. Fortunately chlorpromazine was introduced in the United States in 1954 and proved a safer and saner method of producing institutional tranquility and more frequent release into the community.

Freeman dissented, and after he retired from George Washington University his practice was largely concerned with follow-up studies which he never subjected to rigorous statistical analysis.

Work, the road to fame, consumed him and his marriage crumbled, as much the result of his insistence on a written guarantee about the religious upbringing of future children on his wedding night as his serial infidelities. As he wrote in his notes a short time before his death in May 1972, he "waited in vain for an honorary degree of which my grandfather had six or seven".

His biographer has used his treasure trove with skill and compassion to make a book that deserves to be widely read. El-Hai chose his epigraph from Macbeth's request to Lady Macbeth's physician for surgical or chemical relief of her demented state. Perhaps, a fitting epitaph for Freeman might be Macbeth's only spur: 